\title{
An Algorithmic Approach for the Surgical Treatment of Bone Metastases
}

\author{
Önder KILIÇOĞLU
}

Department of Orthopedics and Traumatology, Koç University Hospital, İstanbul-Turkey

\section{Introduction}

Bone metastases usually indicate an advanced stage of cancer, and surgical treatment is usually palliative.[1] In 2004, the Scandinavian Study Group reported that 1 -year survival was $40 \%$ and 3 -year survival was $20 \%$ in patients who underwent surgical treatment for nonvertebral skeletal metastasis.[2]

The aims of surgical treatment are alleviating pain, restoring function, preventing local progression of the tumor, preserving the patient's quality of life, and in some cases, prolonging life.[3] Most of these can be managed with radiotherapy and medical oncological treatment. However, it takes a long time to increase the mechanical strength of the bone and restore function with radiotherapy, and the risk of fracture persists. [4] Wedin et al.[5] reported that approximately $20 \%$ of the patients with symptomatic bone metastasis, who were referred to them, required surgery.

There are important differences between the approach to non-pathological and pathological bone fractures. Conventional treatments used in nonpathological fractures may not be appropriate for pathological fractures that have occurred or are impending. Pathological fractures are likely to result in implant failures despite medical treatment or radiotherapy after classical osteosynthesis techniques have been applied by targeting the "union" of the bone. Considering the general condition of these patients, the treatment applied should outlast the life of the patient. Thus, surgical treatment may not be the best approach for every patient. The decision of surgical treatment is one that the surgeon and the patient must make together, after considering many factors. When we examined the literature, we found that the most important factors were: 1) life expectancy of the patient, 2) presence of an impending or occurred pathological fracture, 3) histology of the primary tumor, and 4) location of the metastasis.

\section{Life Expectancy of the Patient}

Survival primarily depends on the type of the primary tumor and the visceral tumor burden. Survival is generally higher in multiple myeloma (average 26.3 months), thyroid (average 26 months), breast (average 19 months), and prostate cancers (average 18 months). Average survival is generally poorer in cancers of unknown primary origin and the lungs. Since orthopedic interventions include a wide range of surgical options ranging from tumor resection or prophylactic nailing to megaprosthesis, the answer to whether surgery is required can be provided by determining the patient's life expectancy. For example, if the expected survival of a patient with a pathological proximal femur fracture is very short, nailing may be sufficient for the painless mobilization of the patient with short operation time and less morbidity; prosthesis, on the other hand, may be preferred for a patient with a longer life expectancy.

Although estimating survival is not always easy and reliable, survival probabilities for $1,3,6,12,18$, and 24 months after orthopedic surgery can be determined by PATHFx (www.pathfx.org), which is a validated application. [5-8] General treatment recommendations of the Karolinska University Hospital, depending on the prob- 
ability of survival, may provide valuable suggestions in this regard. [4] Survival estimation calculated according to PATHFx is used in these recommendations. According to the recommendations, if the patient has:

Less than $50 \%$ chance of living for more than three months

- Intramedullary nailing for long bone metastases

- No spinal and pelvic surgery

More than $50 \%$ chance of living for more than six months

- Prosthesis instead of intramedullary nailing

- Reverse shoulder prosthesis in the shoulder

More than 50\% chance of living for more than 12 months

- Total hip prosthesis in a functional patient

- Wide resection for solitary metastasis of renal cell carcinoma

- Advanced reconstruction of the vertebra and the pelvis

The most prominent point in these recommendations is the use of implants with longer survival (such as prosthesis instead of nails) and more radical interventions as survival expectancy increases.

\section{Presence of an Impending or Occurred Patho- logical Fracture}

Pathological fractures either take a long time to heal or often do not heal completely.[9] Therefore, survival expectancy affects the presence of pathological fractures. Although the literature indicates that surgery is generally preferred in patients with a life expectancy of more than six weeks, some studies recommend surgery to alleviate pain even in patients with very short life expectancy. The basic aim is to ensure maximum stability. Ideally, the lesion should be bypassed and mechanical load should be transferred to the healthy bones. The surgery performed should allow immediate full weight-bearing in the post-operative period and should require minimal rehabilitation.

In long bone lesions, Mirels' criteria are commonly used to decide whether an operation is necessary for patients who do not have a pathological fracture but are at risk of one (Table 1).[10] A Mirels' score of 8 and above indicates that prophylactic stabilization should be considered.

Using a score, as in the case of long bones, to evaluate impending pathological fractures in the pelvis is not very useful or possible due to the complex anatomy of the pelvis. Instead, the functional effect of the tumor

\begin{tabular}{|c|c|c|c|c|}
\hline Table & The scoring & method develc & ped by Mi & lirels[10] \\
\hline Score & Location & $\begin{array}{c}\text { Radiographic } \\
\text { view }\end{array}$ & $\begin{array}{l}\text { Affected } \\
\text { bone } \\
\text { width }\end{array}$ & Pain \\
\hline 1 & Upper limb & Blastic & $<1 / 3$ & Mild \\
\hline 2 & $\begin{array}{l}\text { Lower limb } \\
\text { except for } \\
\text { peritrochanteric }\end{array}$ & Mix & $1 / 3-2 / 3$ & Moderate \\
\hline 3 & Peritrochanteric & Lytic & $>2 / 3$ & $\begin{array}{c}\text { Functional } \\
\text { pain }\end{array}$ \\
\hline
\end{tabular}

is evaluated by analyzing the location of the lesion and cortex destruction.

\section{Histology of the Primary Tumor}

In general, it has been shown that wide resection of solitary renal cell carcinoma and thyroid carcinoma metastases can contribute to survival, although resection of the tumor with clear borders (e.g., in primary tumors) is not aimed at metastases. $[11,12]$

\section{Location of Metastasis}

The location of the metastatic lesion is one of the most important factors determining the decision to undergo surgical treatment. When we searched the orthopedic literature, we found that different approaches had been taken depending on whether the lesion was in the long bones, vertebra, or pelvis. The consensus regarding the approach to metastatic lesions in long bones is more than that for the pelvis and vertebra. Operation is rarely preferred for pathological fractures in the pelvis, other than at the acetabulum.[1] Case-based solutions and patient-oriented applications are more common for pelvic lesions.

\section{Long Bones}

The main indications for surgical treatment of metastases in the long bones are pathological fractures that have occurred or are imminent and pain that cannot be relieved.[1] The next step for a patient with long bone metastasis and high life expectancy is to evaluate the risk of the pathological fracture. The choice of the surgical technique and the implant to be used should be made depending on the part of the bone the lesion is located in. Weber et al.[13] proposed the treatment algorithm presented in Figure 1 for long bone metastatic lesions in the lower extremity. 

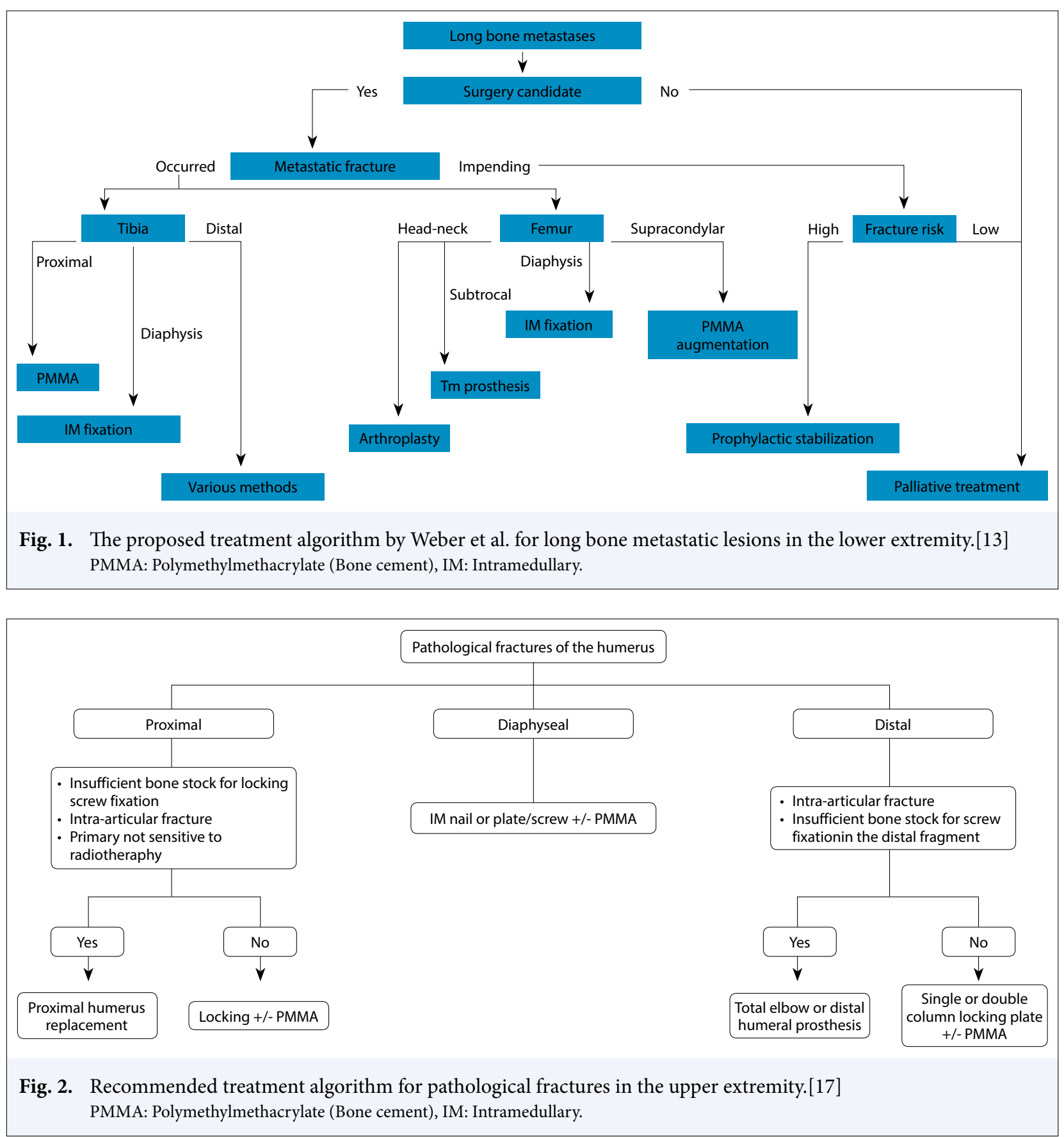

Intramedullary nailing is the most widely accepted method in diaphyseal metastases since they are technically easy, minimally invasive, and cause less bleeding. Additionally, they are able to withstand the load of the bones because they are placed along the axis of the bone. For providing maximum support, the thickest nail available should be used, locked proximally and distally, and the length of the nail should necessarily cover the entire length of the bone. In cases where normal bone healing is not expected, this is an important advantage over osteosynthesis with plate screws and allows early mobilization. Evidence suggests that the use of prostheses in lesions around the proximal femur and hip involves better pain reduction and a lower risk of failure.[5] When osteointegration is not expected, a cemented prosthesis should be preferred. If osteosynthesis is to be performed with plate screws, absolute stability should be targeted, and 
rigid osteosynthesis should be performed. If there is a lytic lesion, curettage followed by cementing can be used for local treatment.

Most of the metastatic lesions in the upper extremity are found in the humerus. Approximately two-thirds of the pathological fractures in the humerus are in the proximal region.[14] Metastasis in the scapula is extremely rare, and most cases can be managed with symptomdirected medical therapy and radiotherapy.[15] Resection or total scapulectomy should only be performed as a last resort. Similarly, metastatic lesions in the forearm and its distal end are extremely rare. These metastases, also called acrometastases, generally indicate poor prognosis and an average survival of six months.[16] Since they are so rare, there is no standard surgical algorithm. Although it can be managed with conservative treatment whenever possible, surgical treatment should be decided on a case-by-case basis.[17]

There are some commonly accepted surgical approaches for the humerus. Voskuil et al.[17] proposed the algorithm presented in Figure 2 for pathological fractures in the upper extremity in an article published in 2021.

\section{Pelvic Metastases}

One of the most important factors determining the treatment of pelvic metastases is the location of the lesion. Metastases in the ilium and pubis do not impair pelvic stability and function. On the other hand, metastases adjacent to the sacroiliac joint and periacetabular threaten the lumbosacral integrity and hip joint. Radiotherapy is effective in reducing pain in approximately $60 \%$ of patients and is the standard treatment method in most cases. Capanna and Müller proposed the algorithm shown in Figure 3 for conditions that require surgery, such as the risk of pathological fractures or persistent pain.[18]

\section{Vertebral Metastases}

In vertebral metastases, operative treatment is generally considered in patients with spinal instability, neurological symptoms, or persistent pain. Rapidly developing neurological deficit is an indication for emergency surgery. Healing after operations for pathological fractures in the vertebra takes longer than that in the long bones; additionally, complication rates are also higher. $[19,20]$ Therefore, patients with a life expectancy of fewer than three months generally do not benefit from spinal surgery. [4]

When we examined the literature, we found that surgery for spinal metastases is more heterogeneous

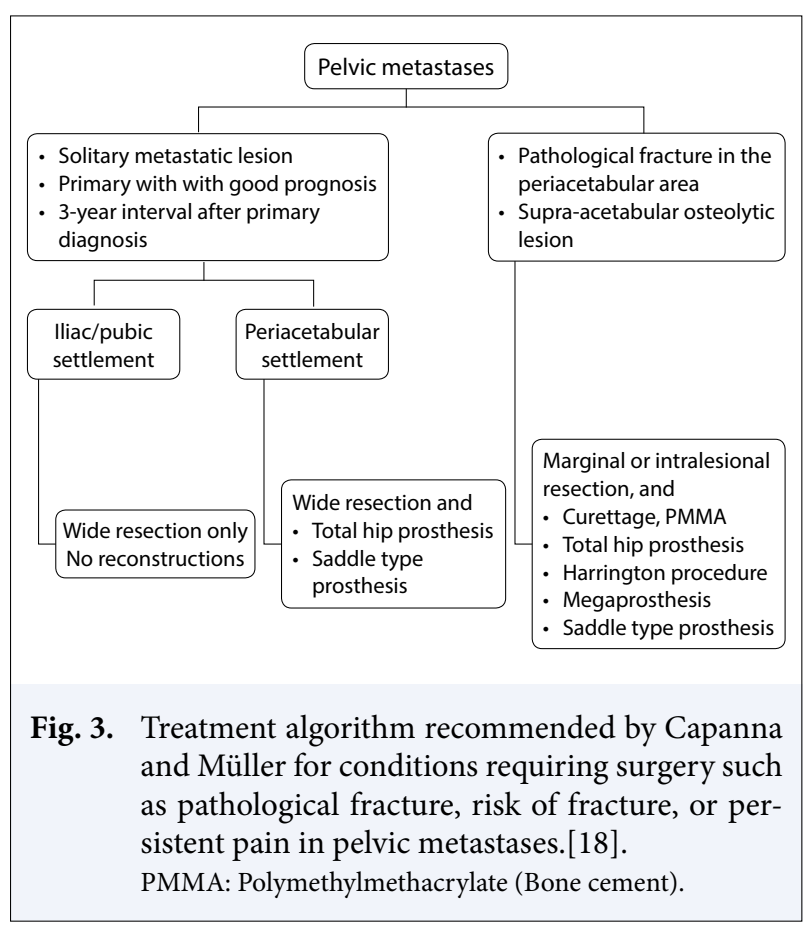

than for long bones. For example, Bauer et al.[21] from the Karolinska Institute reported that they operated almost only on patients with neurological symptoms. The scoring method developed by Tomita et al.[22] is used to decide how aggressive the surgical intervention will be. Smaller interventions or palliative treatment are recommended for patients who get a high score by this method (Table 2). Table 2 The scoring method developed by Tomita et
al.[22]

\section{Primary tumor growth rate}

\section{Score}

Slow (breast, prostate, thyroid)

Moderate (kidney, uterus)

Fast (lung, liver, stomach,

colon, of unknown primary)

Visceral metastases

None

Treatable

Untreatable

Bone metastases

Solitary

Multiple

Total score
2-4
4-6
6-8
8-10
En bloc resection
Debulking surgery
Palliative decompression
Supportive therapy 


\section{References}

1. Bickels J, Dadia S, Lidar Z. Surgical management of metastatic bone disease. J Bone Joint Surg Am 2009;91(6):1503-16.

2. Hansen BH, Keller J, Laitinen M, Berg P, Skjeldal S, Trovik C, et al. The Scandinavian Sarcoma Group skeletal metastasis register survival after surgery for bone metastases in the pelvis and extremities. Acta Orthop Scand 2004;75(sup311):11-5.

3. Katzer A, Meenen NM, Grabbe F, Rueger J. Surgery of skeletal metastases. Arch Orthop Trauma Surg 2002;122(5):251-8.

4. Tsagozis P, Forsberg J, Bauer HCF, Wedin R. How expected survival influences the choice of surgical procedure in metastatic bone disease. In: Denaro V, Di Martino A, Piccioli A, editors. Management of Bone Metastases. Springer; 2019. p. 49-54.

5. Wedin R. Surgical treatment for pathologic fracture. Acta Orthop Scand 2001;72(4):1-29.

6. Forsberg JA, Wedin R, Bauer HCF, Hansen BH, Laitinen $\mathrm{M}$, Trovik CS, et al. External validation of the Bayesian Estimated Tools for Survival (BETS) models in patients with surgically treated skeletal metastases. BMC Cancer 2012;12(1):1-8.

7. Piccioli A, Spinelli MS, Forsberg JA, Wedin R, Healey $\mathrm{JH}$, Ippolito V, et al. How do we estimate survival? External validation of a tool for survival estimation in patients with metastatic bone disease-decision analysis and comparison of three international patient populations. BMC Cancer 2015;15:424.

8. Forsberg JA, Wedin R, Boland PJ, Healey JH. Can we estimate short-and intermediate-term survival in patients undergoing surgery for metastatic bone disease? Clin Orthop Relat Res 2017;475(4):1252-61.

9. Jacofsky DJ, Haidukewych GJ. Management of pathologic fractures of the proximal femur: state of the art. J Orthop Trauma 2004;18(7):459-69.

10. Mirels H. Metastatic disease in long bones. A proposed scoring system for diagnosing impending pathologic fractures. Clin Orthop Relat Res 1989;(249):256-64.
11. Baloch KG, Grimer RJ, Carter SR, Tillman RM. Radical surgery for the solitary bony metastasis from renalcell carcinoma. J Bone Joint Surg Br 2000;82(1):62-7.

12. Stojadinovic A, Shoup M, Ghossein RA, Nissan A, Brennan MF, Shah JP, et al. The role of operations for distantly metastatic well-differentiated thyroid carcinoma. Surgery 2002;131(6):636-43.

13. Weber KL, Randall RL, Grossman S, Parvizi J. Management of lower-extremity bone metastasis. J Bone Joint Surg Am 2006;88 Suppl 4:11-9.

14. Toepfer A, Lenze U, Pohlig F, Eisenhart-Rothe Rv, Gerdesmeyer L, Kirchhoff C, et al. Pathological fractures of the humerus: experience with 76 cases in a musculoskeletal oncology centre. Z Orthop Unfall 201;154(4):364-9.

15. Thai DM, Kitagawa Y, Choong PF. Outcome of surgical management of bony metastases to the humerus and shoulder girdle: a retrospective analysis of 93 patients. Int Semin Surg Oncol 2006;3:5.

16. Stomeo D, Tulli A, Ziranu A, Perisano C, De Santis V, Maccauro G. Acrometastasis: a literature review. Eur Rev Med Pharmacol Sci 2015;19(15):2906-15.

17. Voskuil RT, Mayerson JL, Scharschmidt TJ. Management of metastatic disease of the upper extremity. J Am Acad Orthop Surg 2021;29(3):e116-e25.

18. Müller DA, Capanna R. The surgical treatment of pelvic bone metastases. Adv Orthop 2015;2015:525363.

19. Wedin R, Bauer HC, Wersäll P. Failures after operation for skeletal metastatic lesions of long bones. Clin Orthop Relat Res 1999;(358):128-39.

20. Wise JJ, Fischgrund JS, Herkowitz HN, Montgomery D, Kurz LT. Complication, survival rates, and risk factors of surgery for metastatic disease of the spine. Spine (Phila Pa 1976) 1999;24(18):1943-51.

21. Bauer HC. Posterior decompression and stabilization for spinal metastases. Analysis of sixty-seven consecutive patients. J Bone Joint Surg Am 1997;79(4):514-22.

22. Tomita K, Kawahara N, Kobayashi T, Yoshida A, Murakami $\mathrm{H}$, Akamaru T. Surgical strategy for spinal metastases. Spine (Phila Pa 1976) 2001;26(3):298-306. 